\title{
Se isotopic fractionation as a result of oxidation of Se-bearing minerals
}

\author{
NAOMI L. WASSERMAN ${ }^{1}$ KATHRIN SCHILLING $^{2}$ THOMAS \\ M. JOHNSON ${ }^{1}$ CÉLINE PALLUD $^{3}$ \\ ${ }^{1}$ Department of Geology, University of Illinois at Urbana- \\ Champaingn, Urbana, IL (*nwasser2@illinois.edu) \\ ${ }^{2}$ Lamont-Doherty Earth Observatory, Palisades, NY \\ ${ }^{3}$ Department of Environmental Science, Policy, and \\ Management, UC Berkeley, Berkeley, CA
}

Selenium (Se) is a micronutrient, but also toxic at moderate concentrations to humans and animals (EPA MCL: $50 \mu \mathrm{g} / \mathrm{L})[1]$. Oxidation of insoluble reduced Se, like $\mathrm{Se}(0)$ and $\mathrm{Se}(-\mathrm{II})$-bearing minerals, leads to the formation of soluble $\mathrm{Se}(\mathrm{IV})$ and $\mathrm{Se}(\mathrm{VI})$ oxyanions, both of which can be attenuated in natural systems through adsorption or reduction. As a result of both of these reactions, Se stable isotopes fractionate and are used to monitor remediation efforts of Secontaminated waters $[2,3,4]$. Oxidation of reduced Se has been thought to produce negligible isotopic fractionation. However, complex incongruent dissolution of a Se-bearing mineral could result in persistant isotopic fractionation.

We present experiments that examine Se isotope effects associated with oxidation of ferroselite $\left(\mathrm{FeSe}_{2}\right)$, berzelianite $\left(\mathrm{Cu}_{2} \mathrm{Se}\right)$, and Se-rich arsenopyrite (FeAsS) with $\mathrm{H}_{2} \mathrm{O}_{2}$. Continuously-stirred batch reactors containing each mineral and synthetic groundwater were amended with $0.4 \mathrm{mM} \mathrm{H}_{2} \mathrm{O}_{2}$ or $1 \mathrm{mM} \mathrm{H}_{2} \mathrm{O}_{2}$. Se concentrations for all conditions reached steady state by $72 \mathrm{hrs}$. Oxidation of berzelianite with $0.4 \mathrm{mM}$ $\mathrm{H}_{2} \mathrm{O}_{2}$ results in $\delta^{82} \mathrm{Se} /{ }^{76} \mathrm{Se}$ of dissolved $\mathrm{Se}(\mathrm{VI})$ that is $3 \%$ o heavier than dissolved Se(IV), which increases from $1 \%$ lighter to $0.5 \%$ heavier than the unreacted mineral. Oxidation of berzelianite with $1 \mathrm{mM} \mathrm{H} \mathrm{H}_{2} \mathrm{O}_{2}$ shows a similar trend initially, but the $\mathrm{Se}(\mathrm{VI})$ fraction returns to unfractionated values by the end of the experiment. These results indicate that in addition to isotopic fractionation during initial oxidative dissolution, kinetic isotopic fractionation during oxidation of $\mathrm{Se}(\mathrm{IV})$ results in isotopically heavy $\mathrm{Se}(\mathrm{VI})$ for the less oxic condition. For the ferroselite oxidation dissolved $\mathrm{Se}(\mathrm{IV})$ and $\mathrm{Se}(\mathrm{VI})$ become immediately isotopically heavy under both conditions due to re-reduction by iron sulfide. In the less oxic condition, Se(IV) evolves to be 3\%o lighter than $\mathrm{Se}(\mathrm{VI})$ at the end of the experiment due to isotopic fractionation during the oxidation of Se(IV). Thus, the oxidative dissolution of $\mathrm{Se}(-\mathrm{II})$-bearing minerals produces isotopically heavy Se on short timescales, and should be considered when using Se isotopes to examine modern or ancienct Se biogeochemical cycling. [1] EPA (2019) Natl. Prim. Drinking Water Reg., [2] Herbel et al. (2000) GCA, [3] Basu et al. (2016) ES\&T [4] Xu et al. (2020) GCA 